\title{
Ergonomic Design of Human-CNC Machine Interface
}

\author{
Imtiaz Ali Khan \\ Department of Mechanical Engineering, \\ Aligarh Muslim University, Aligarh, \\ India
}

\section{Introduction}

Ever since the industrial revolution opened the vistas of a new age, the process of industrialization has been at the core of the economic development of all countries. In a simple sense, industrialization means replacement of human labor by machinery to manufacture goods. In this way it induces a shift from home (craft) to factory based production. In a more rational sense, it is a process whereby the share of industry in general and manufacturing in particular, in total economic activities increases.

Worldwide the machine tool industry is a small manufacturing sector, but widely regarded as a strategic industry as it improves overall industrial productivity through supplying embodied technology. The introduction of computer numerically controlled (CNC) has rejuvenated the market. The production and trade have been mostly concentrated in industrialized countries accounting for more than two-thirds of share. However, it is gaining importance among developing countries. The production of high-end machines is concentrated in the USA, Germany Switzerland and Japan. In the mid-range segment Japan is the market leader. In the low-end segment Taiwan and Korea are predominant.

Ergonomics (Human Factors Engineering) is concerned with the 'fit' between people and their technological tools and environments. It takes account of the user's capabilities and limitations in seeking to ensure that tasks, equipment, information and the environment suit each user. To assess the fit between a person and the used technology, ergonomists consider the job (activity) being done and the demands on the user; the equipment used (its size, shape, and how appropriate it is for the task), and the information used (how it is presented, accessed, and changed). The term 'ergonomics' is generally used to refer to physical ergonomics as it relates to the workplace (as in for example ergonomic chairs and keyboards). Physical ergonomics is important in the medical field, particularly to those diagnosed with physiological ailments or disorders such as arthritis (both chronic and temporary) or carpal tunnel syndrome. Ergonomics in the workplace has to do largely with the safety of employees, both long and short-term. Ergonomics can help reduce costs by improving safety. This would decrease the money paid out in workers' compensation. For example, over five million workers sustain overextension injuries per year. Through ergonomics, workplaces can be designed so that workers do not have to overextend 
themselves and the manufacturing industry could save billions in workers' compensation. Workplaces may either take the reactive or proactive approach when applying ergonomics practices. Reactive ergonomics is when something needs to be fixed, and corrective action is taken. Proactive ergonomics is the process of seeking areas that could be improved and fixing the issues before they become a large problem. Problems may be fixed through equipment design, task design, or environmental design. Equipment design changes the actual, physical devices used by people. Task design changes what people do with the equipment. Environmental design changes the environment in which people work, but not the physical equipment they use.

Ergonomics literature provides ample evident of many successful ergonomic interventions and their positive impact for both employees and employers of all sectors of the society. It is generally accepted that the application of ergonomics is essential for improving working conditions, system efficiency and promotion of the working-life quality. While ergonomics has shown good potential for ensuring optimum technology utilization and proper technological development in the industrialized world, interest and attention paid to the subject is very low among organizations and industrial managers in the industrially developing countries. Almost, two-thirds of the world population in these countries has little or no access to the vast knowledge base that makes ergonomics such an important tool for improving work environment and increase productivity (Shahnavaz et al. 2010). When applying the appropriate type of ergonomics, there would be improvements in quality, productivity, working conditions, occupational health and safety, reduction of rejects and increases in profit (Yeow and Sen, 2002). Ergonomics intervention and its potential to deliver benefits has been accepted and practiced worldwide. The term intervention refers to efforts made to effect change and render such change stable and permanent (Westlander et al. 1995). The objective of ergonomics intervention is to design jobs that are possible for people to do, are worth doing and which give workers job satisfaction and a sense of identity with the company and protect and promote workers' health. Ergonomics intervention should therefore result in improving both the employees' wellbeing (health, safety and satisfaction) as well as the company's wellbeing (optimal performance, productivity and high work quality) (Shahnavaz, 2009).

Companies once thought that there was a bottom-line tradeoff between safety and efficiency. Now they embrace ergonomics because they have learned that designing a safe work environment can also result in greater efficiency and productivity. Recently, U.S. laws requiring a safe work environment have stimulated great interest in Ergonomics - from ergonomic furniture to ergonomic training. But it is in the design of the workplace as a whole where the greatest impact can be seen for both safety and efficiency. The easier it is to do a job, the more likely it is to see gains in productivity due to greater efficiency. Analogously, the safer it is to do a job, the more likely it is to see gains in productivity due to reduced time off for injury. Ergonomics can address both of these issues concurrently by maximizing the workspace and equipment needed to do a job.

Today, Ergonomics commonly refers to designing work environments for maximizing safety and efficiency. Biometrics and Anthropometrics play a key role in this use of the word Ergonomics. Anthropometry refers to the measurement of the human individual for the purposes of understanding human physical variation. Today, anthropometry plays an important role in industrial design, ergonomics and architecture where statistical data about 
the distribution of body dimensions in the population are used to optimize products. Changes in life styles, nutrition and ethnic composition of populations lead to changes in the distribution of body dimensions and require regular updating of anthropometric data collections. Engineering Psychology often has a specialty dealing with workplace or occupational Ergonomics. While health and safety has always been a dynamic and challenging field, individuals now are being asked to demonstrate cost savings with resources that are more limited than ever. How do companies meet the expectations of "doing more with less" in the health and safety field? One approach that has proven effective in scores of manufacturing companies is to leverage the efforts of ongoing improvement initiatives to accelerate ergonomics improvements.

Recent developments in the field of information and communication technologies and specialized work requiring repetitive tasks have resulted in the need for a human factor engineering approach. Through examining, designing, testing and evaluating the workplace and how people interact in it, human factor engineering can create a productive, safe and satisfying work environment. With the high technology applications getting more widespread at the global level the problems associated with the introduction of this hi-tech have also been generating more concern. Most part of such concern is reflected in occupational stresses in the form of poor job performance, waste leisure time, low level of job satisfaction, alcohol related problems and hence forth. One most notable component of hi-tech era emerged in the shape of human-CNC machine interaction (HMI) that basically comprises of a CNC workstation and an operator. The use of CNC systems is increasing exponentially. This is accompanied with a proportionate increase in occupational stresses too in human operators. Previous studies pertaining to HMI by different researchers in the field revealed that all sorts of problems associated with the use of CNC machines could be traced in terms of physical characteristics of the CNC workstation, visual factors, psychological factors and postural factors. Present studies mainly associated to the last said factor that relates to constrained postures of the $\mathrm{CNC}$ operators governed by the characteristics of given workstation. It is well documented that the constrained posture is always associated with static muscular efforts that might lead subsequently to muscular fatigue in humans. If such a postural stress is allowed to persist on a prolonged basis it may adversely affect not only the muscles, but also the joint systems, tendons and other tissues.

Factors such as work environment and the work performed are crucial from the ergonomic design point of view. Preferred term for conditions that are subjectively or objectively influenced or caused by the work is musculoskeletal disorder. Many occupations are associated with a high risk of arm and neck pain. Some risk factors can be identified, but the interaction between the factors is not much understood. It is important to recognize personal characteristics and other environmental and socio-cultural factors which usually play a key role in these disorders. Working with hands at or above the shoulder level may be one determinant of rotator cuff tendinitis. Industrial workers exposed to the tasks that require working over shoulder level include panel controlled CNC machine operators, shipyard welders, car assemblers, house painters and so on. Disorder and pain in the arm have been related to the gripping an instrument and awkward posture. Several factors which are considered to influence the static activity of the shoulder muscles are horizontal distance between the worker and the working place, position of the task, height of the working table, shoulder joint flexion, abduction/adduction and the posture etc. (Westgaard et al. 1988). Disorder and visual discomfort have been related to the visual display unit (VDU) position 
and awkward posture. Factors which are considered to influence the activity of the eye muscles are horizontal distance between the worker and height of the VDU screen and the posture etc. (Westgaard et al., 1988). Present work is taken to develop a better understanding of the effect of angle of abduction and viewing angle in a HMI environment. The CNC-EDM interaction system was targeted keeping in-view the exponential growth of the automation nowadays and the use of CNC machines in manufacturing and design. Therefore, the need of the moment is an efficient and effective ergonomic design of the CNC-workstations. Unorganized CNC machine working environment which does not meet the human capabilities is considered as a major source of stress and errors. Review of literature suggests that the original sources of postural stresses may be traced in terms of poor CNC workstation design. In recent years, the major emphasis is on preventing musculoskeletal injuries in the workplace. These injuries create a significant cost for industry.

Many of the injuries in manufacturing are musculoskeletal disorders caused by cumulative trauma. We call these injuries that result from cumulative wear and tear, cumulative trauma disorders (CTDs). Back injuries, tendinitis and carpal tunnel syndrome are examples of common CTDs. Workplace risk factors for CTDs include repetitive motions, high forces, awkward postures and vibration exposure. CTDs in manufacturing can be associated with such activities as manual material handling, hand tool usage, awkward postures and prolonged equipment operation. One effective way to reduce the risk of CTDs such as carpal tunnel syndrome and back injuries is to establish an ergonomic process. Do not regard an ergonomic processes as separate from those intended to address other workplace hazards. Use the same approaches to address ergonomic processes issue-hazard identification, case documentation, assessment of control options and healthcare management techniques that you employ to address other safety problems. It is important to realize that you cannot combat cumulative disorders effectively with a quick-fix program. Rather, a long-term process, which relies on continuous improvement, is the preferred approach to reducing CTDs. Successful programs not only result in reduction of injuries, but they achieve quality and productivity gains, as well. For an ergonomic process to be successful, it is imperative that management is committed to the process, participates in the process and provides the necessary resources to ensure its success. Nowadays, efforts in health promotion programs have increased. Notwithstanding, work related musculoskeletal disorders (WMSDs) remain a widespread and growing issue of concern in the automated manufacturing industry. In the coming years, WMSDs leading to absence and reduced employment ability along with an aging work force with comparatively high wages will become an even greater challenge to these automated manufacturing companies facing worldwide competition. The prevention of WMSDs is achieved through improvements in the design of working conditions and tasks as well as through influencing the health promoting behavior of individuals. What is needed, nowadays, is a systematic approach, that enables automated industries to identify and control physical stress at work that leads to WMSDs in a comprehensive manner.

The most important considerations in the human-CNC machine interaction environment are the angle of abduction and viewing angle, which plays a key role in system design. Hence, their effect on human performance in a CNC-EDM environment has been explored in this work. 


\section{Related works}

The rapid growth of automation has led to the development of research on human- machine interaction environment. The research aims at the design of human-machine interfaces presenting ergonomic properties such as friendliness, usability, transparency and so on. Recently public and private organizations have engaged themselves in the enterprise of managing more and more complex and coupled systems by means of the automation. Modern machines not only process information but also act on the dynamic situations as humans have done in the past like managing manufacturing processes, industrial plants, aircrafts etc. These dynamic situations are affected by uncertain human factors. The angle of abduction and viewing angle are considered frequently in the design of the systems like human-computer interaction, human-CNC machine interaction and so on. A review of the literature finds a relatively large number of studies on the angle of abduction and viewing angle. The influence of external factors such as arm posture, hand loading and dynamic exertion on shoulder muscle activity is needed to provide insight into the relationship between internal and external loading of the shoulder joint as explored by Antony et al. (2010). The study collected surface electromyography from 8 upper extremity muscles on 16 participants who performed isometric and dynamic shoulder exertions in three shoulder planes (flexion, mid-abduction and abduction) covering four shoulder elevation angles $\left(30^{\circ}\right.$, $60^{\circ}, 90^{\circ}$ and $120^{\circ}$ ). Shoulder exertions were performed under three hand load conditions: no load, holding a $0.5 \mathrm{~kg}$ load and $30 \%$ grip. It was found that adding a $0.5 \mathrm{~kg}$ load to the hand increased shoulder muscle activity by $4 \%$ maximum voluntary excitation (MVE), across all postures and velocities. Kuppuswamy et al. (2008) determined that the abduction of one arm preferentially activates erector spinae muscles on the other side to stabilize the body. The study hypothesizes that the corti cospinal drive to the arm abductors and the erector spinae may originate from the same hemisphere. Terrier et al. (2008) explored that the shoulder is one of the most complex joints of the human body, mainly because of its large range of motion but also because of its active muscular stabilization. The study presented an algorithm to solve the indeterminate problem by a feedback control of muscle activation, allowing the natural humorous translation. In this study the abduction was considered in the scapular plane, accounting for the three deltoid parts and the rotator cuff muscles. Gutierrez et al. (2008) determined the effects of prosthetic design and surgical technique of reverse shoulder implants on total abduction range of motion and impingement on the inferior scapular neck. The study concluded that the neck-shaft angle had the largest effect on inferior scapular impingement, followed by glen sphere position. Levasseur et al. (2007) explored that a joint coordinate system allows coherence between the performed movement, its mathematical representation and the clinical interpretation of the kinematics of joint motion. The results obtained revealed a difference in the interpretation of the starting angles between the International Society Biomechanics (ISB) joint coordinate system and the aligned coordinate system. No difference was found in the interpretation of the angular range of motion. Wickham et al. (2010) performed an experiment to obtain electromyography (EMG) activity from a sample of healthy shoulders to allow a reference database to be developed and used for comparison with pathological shoulders. In this study temporal and intensity shoulder muscle activation characteristics during a coral plane abduction/adduction movement were evaluated in the dominant healthy shoulder of 24 subjects. The study concluded that the most reproducible patterns of activation arose from the more prime movers muscle sites in all EMG variables analyzed and although variability 
was present, there emerged invariant characteristics that were considered normal for this group of non pathological shoulders. Gielo-Perczak et al. (2006) conducted a study to test whether glen humeral geometry is co-related with upper arm strength. The isometric shoulder strength of 12 subjects during one-handed arm abduction in the coronal plane in a range from $5^{0}$ to $30^{\circ}$, was correlated with the geometries of their glenoid fossas. The study concluded that the new geometric parameter named as the area of glenoid asymmetry (AGA) is a distinguished factor which influence shoulder strength when an arm is abducted in a range from $5^{0}$ to $30^{\circ}$. Mukhopadhyay et al. (2007) explored that industrial jobs involving upper arm abduction have a strong association with musculoskeletal disorders and injury. Biomechanical risk factors across different mouse positions within a computer controlled workstation were explored by Dennerlein et al. (2006). One of the two studies with 30 subjects (15 females and 15 males) examined the three mouse positions: a standard mouse (SM) position with the mouse placed to the right of the keyboard, a central mouse (CM) position with the mouse between the key board and the human body and a high mouse (HM) position using a keyboard drawer with the mouse on the primary work surface. The second study examined two mouse positions: the SM position and a more central position using a different keyboard (NM). In this work the muscle activity of the wrist and upper arm postures were recorded through the electromyography technique. The CM position was found to produce the most neutral upper extremity posture across all measures. The HM position has resulted the least neutral posture and highest level of muscle activity. The study also indicated that the NM position reduces wrist extension slightly and promote a more neutral shoulder posture as compared to the SM position. The study concluded that the HM position was least desirable whereas the CM position result the minimum awkward postures. Peter et al. (2006) determined the differences in biomechanical risk factors during the computer tasks. The study was conducted with the 30 touch-typing adults (15 females and 15 males). The subjects were asked to complete five different tasks: typing text, filling of a html form with text fields, text editing within a document, sorting and resizing objects in a graphics task and browsing and navigating a series of internet web pages. The study reported that the task completion with the help of both the mouse and the keyboard result the higher shoulder muscle activity, larger range of the motion and the larger velocities and acceleration of the upper arm. Susan et al. (2006) reported large and statistically significant reductions in muscle activity by modifying a workstation arrangement of an ultrasound system's control panel. In this study, the right suprascapular fossa activity indicated a reduction of muscle activity by $46 \%$, between a postural stance of 75 and 30 degrees abduction. Choudhry et al. (2005) in their study compared the anthropometric dimensions of the farm youths of the north-eastern region of the India with those of China, Japan, Taiwan, Korea, Germany, Britain and USA. The study concluded that all the anthropometric dimensions of the Indian subjects were lower than those from the other parts of the world. Human laterality is considered to be one of the most important issues in human factors engineering. Hand anthropometric data have indicated differences between right and left-handed individuals and between females and males. A study was carried out by Yunis (2005) on the hand dimensions of the right and left-handed Jordanian subjects. The results indicated that there were significant differences in the hand anthropometric data between right and left-handed subjects as well as between the females and males subjects. Alan et al. (2003) explored in their study that the constant intramuscular (IMP) / EMG relationship with increased force may be extended to the dynamic contractions and to the fatigued muscles. In this study IMP and EMG patterns were 
recorded through shoulder muscles in the three sessions. It was found in the study that during the brief static tasks the IMP and EMG patterns increased with the shoulder torque. Jung-Yong et al. (2003) determined the upward lifting motion involved at the scapula at various shoulder angles. In particular, 90 and 120 degrees of flexion, 30 degrees of adduction, and 90 degrees of abduction were found to be the most vulnerable angles based on the measured maximum voluntary contractions (MVCs). The average root mean square value of the EMG increased most significantly at 90 to 150 degrees of flexion and at 30 and 60 degrees of abduction. The increasing demand of the anthropometric data for the design of the machines and personal protective equipments to prevent the occupational injuries has necessitated an understanding of the anthropometric differences among occupations. Hongwei et al. (2002) identified the differences in various body measurements between various occupational groups in the USA. The analysis of the data indicated that the body size or the body segment measurements of some occupational groups differ significantly. The optimum height of the table of the operating room for the laparoscopic surgery was investigated by Smith et al. (2002). The study concluded that the optimum table height should position the handles of the laparoscopic instrument close to the surgeon's elbow level to minimize discomfort. The study determined the optimum table height as 64 to 77 centimeters above the floor level. In the retail supermarket industry where the cashiers perform repetitive light manual material-handling tasks during scanning and handling products, the cases of the musculoskeletal disorders and the discomfort are high. Lehman et al. (2001) conducted a research to determine the effect of working position (sitting versus standing) and scanner type (bi-optic versus single window) on the muscle activity. Ten cashiers from a Dutch retailer environment participated in the study. Cashiers exhibited the lower muscle activity in the neck and shoulders when standing and using a bi-optic scanner. The shoulder abduction was also less for the standing conditions. Yun et al. (2001) investigated the relationship between the self-reported musculoskeletal symptoms and the related factors among visual display terminals (VDT) operators working in the banks. The subjects of the study were 950 female bank tellers. The study was carried out to specify the prevalence of the WMSDs and to identify the demographic and task-related factors associated with the WMSD symptoms. The study indicated the percentages of the subjects reported the disorders of the shoulder, lower back, neck, upper back, wrist and the fingers as 51.4, 38.3, 38.0, 31.2, 21.7 and 13.6 respectively. Another case study was conducted in an automobile assembly plant by Fine et al. (2000). There were 79 subjects who reported shoulder pain. More than one-half also had positive findings in a physical examination. Subjects who were free of shoulder pain were randomly selected. Forty-one percent of the subjects flexed or abducted the right arm "severely" (above 90 degrees) during the job cycle, and $35 \%$ did so with the left arm. Disorders were associated with severe flexion or abduction of the left (odds ratio (OR) 3.2) and the right (OR 2.3) shoulder. The risk increased as the proportion of the work cycle exposure increased. The findings concluded that, the shoulder flexion or abduction, especially for $10 \%$ or more of the work cycle, is predictive of chronic or recurrent shoulder disorders. David et al. (1988) investigated the effect of the anthropometric dimensions of the three major ethnic groups in the Singapore. The study was carried out with the help of the 94 female visual display units (VDU) operators. Few anthropometric differences were recorded among the Chinese, Malays and Indians. On comparing the data with the Americans and Germans, the three Asian cohorts were found smaller in the body size. Because of the smaller body build the Asian VDU operators preferred a sitting height of about 46 centimeters and a working height of about 74 
centimeters while as the European operators preferred the sitting and working heights as 47 centimeters and 77 centimeters respectively. The position of the upper arm and head, as an indicator of load on the shoulder and risk of shoulder injury for workers performing electromechanical assembly work, was explored by Westgaard et al. (1988). In this study postural angles, in terms of flexion/extension and abduction/adduction of the right upper arm and the shoulder joint, as well as flexion/extension of head and back were measured for a group of female workers. Adopting a posture with an arm flexion of less than 15 degrees, an arm abduction of less than 10 degree and using a light $(0.35 \mathrm{~kg})$ hand tool, resulted in a $20 \%$ incidence of sick leaves due to shoulder injuries of workers employed between 2-5 years, and 30\% incidence for those employed more than 5 years. This was significantly lower for other groups working with higher arm flexion. The study concluded that the magnitude of the postural angles of the shoulder joint influenced the shoulder load. Another study for standing, supported-standing, and sitting postures was carried out with subjects simulating assembly work in places with poor leg space by Bendix et al. (1985). The postures and the upper trapezius muscle load were examined using statometric and electromyography methods, respectively. While supported-standing or sitting, the lumbar spine moved toward kyphosis, even with no backward rotation of the pelvis. In adopting the position for anteriorly placed work, the arms were raised 30 degrees forward or more, the trunk was flexed as well. It was concluded in the study that, if leg space is poor, variation between supported-standing and standing should be encouraged, and an ordinary office chair should be avoided. Also, the working level should be arranged so that it is lower than 5 centimetres above the elbow level if no arm/wrist support is possible.

The viewing angle is considered frequently in the design of the systems like human-computer interaction, human-CNC machine interaction and so on. A review of the literature finds a relatively large number of studies on the viewing angle. Smith et al. (2010) explored that the attention mediates access of sensory events to higher cognitive systems and can be driven by either top-down voluntary mechanisms or in a bottom-up, reflexive fashion by the sensory properties of a stimulus. The study investigated the effect of an experimentally induced opthalmoplegia on voluntary and reflexive attentional orienting during visual search. The study observed that abducting the eye into the temporal hemi field elicited deficits of both voluntary and reflexive attention for targets that appeared beyond the oculomotor range. Kong-King et al., (2007) determined the viewing distance and screen angle for electronic paper (E-Paper) displays under various light sources, ambient illuminations and character sizes. Findings of this study indicate that mean viewing distance and screen angle should be 495 millimetres and 123.7 degrees (in terms of viewing angle, 29.5 degrees below the horizontal eye level), respectively. Proper visualization of the background of surgical field is essential in the laparoscopic surgery and it reduces the risk of iatrogenic injuries. One of the important factors influencing visualization is the viewing distance between surgeon and the monitor. Shallaly et al., (2006) performed an experiment with 14 surgeons. The experiment was designed to determine two working distances from a standard 34 centimeters (14 inch) diagonal cathode ray tube (CRT) monitor: one the maximum view distance permitting small prints of a near vision chart to be identified clearly by sight and second the minimum view distance (of a standard resolution chart) just short of flicker, image degradation or both. The results indicated that the maximum view distance allowing identification averaged 221 centimeters (range 166-302 centimeters). The mean minimal viewing distance short of flicker/image degradation was determined as 136 centimeters (range 102-168 centimeters). For 
most surgeons the extrapolated monitor viewing distances for the laparoscopic surgery ranges from 139 centimeters to 303 centimeters (57-121 inch) for the maximal distance viewing and from 90 centimeters to 182 centimeters (36-73 inch) for close-up viewing (i.e. optimal working range of 90 to 303 centimeters or 36-121 inch). It was concluded that the maximal and minimal (close-up) viewing distances are variable, but the surgeon should never be farther than 3 meters (10 ft.) or closer than 0.9 meter $(3 \mathrm{ft}$.) from the monitor. Another study for visual display unit work environment was carried out by Svensson et al., (2001). In this study two viewing angles, namely 3 degrees above the horizontal and 20 degrees below the horizontal, were considered. The findings concluded that the load on the neck and shoulders was significantly lower at 3 degrees as compared to 20 degrees. Jan et al., (2003) explored that low VDU screen height increases the viewing angle and also affects the activity of the neck extensor muscles. Ayako et al., (2002) determined the effects of the tilt angle of a notebook computer on posture and muscle activities. It was concluded in the study that at 100 degree tilt angle, the subjects had relatively less neck flexion. Visual display units are widely used in the industries. The optimization of their orientation is a critical aspect of the human-machine interaction and impacts on the worker health, satisfaction and performance. Due to increase in the visual and musculoskeletal disorders related to VDU use, a number of ergonomic recommendations have been proposed in order to combat this problem. Fraser et al., (1999) observed that, the monitor position, 18 degree below eye level had no significant effect on the position of the neck relative to the trunk while, the mean flexion of the head, relative to the neck increased 5 degrees. Burgess-Limerick et al., (2000) determined optimal location of the visual targets as 15 degrees below horizontal eye level. Adjustability effect of the touch screen displays in a food service industry was investigated by Batten et al., (1998). To determine the optimal viewing angle or range of a given touch-screen display, an anthropometric analysis was carried out. The results recommended the adjustable range of the touch-screen display as 30 to 55 degrees to the horizontal. Mon-Williams et al., (1998) in their study pointed out that as vertical gaze angle is raised or lowered the 'effort' required to binocular system also changes. The results indicated that the heterophoria varies with vertical gaze angle and stress on the vergence system during the use of HMDs will depend, in part, on the vertical gaze angle. Another case study was conducted by Koroemer et al., (1986). Sixteen male and sixteen female subjects were used in the study. The findings concluded that the subject looks down steeply at an average of 29 degrees below the horizontal, when sitting with the trunk and head upright. Also this angle is steeper when the visual target is at 0.50 meter distance ( $-33 \pm 11.3$ degrees) and flatter when the target is at 1.00 meter ( $-24 \pm 10.4$ degrees).

The reviewed researches have clearly indicated that the musculoskeletal disorder is one of the major factors as far as human injuries in the computer controlled working environment are concerned. The above findings have been used to formulate the present studies of the effect of the angle of abduction and viewing angle in a CNC-EDM interaction environment.

\section{Methodology}

\subsection{Study I}

\subsubsection{Subjects}

Experimental investigation was carried out with three groups of 18 subjects each. Groups were divided according to the variation in height of the subjects; i.e. (Group1) - Subjects of 
height 5' 9", (Group2) - Subjects of height 5' 6" and (Group3) - Subjects of height 5' 4". All subjects were of same sex (i.e. male), age varied from 21-26 years with mean age of $23.72 \mathrm{yrs}$ $(\mathrm{S} . \mathrm{D}=1.592)$ and mean arm length of $28.5 \mathrm{inch}, 28$ inch and 27.5 inch for $5^{\prime} 9^{\prime \prime}, 5^{\prime} 6^{\prime \prime}$ and $5^{\prime} 4^{\prime \prime}$ tall subjects, respectively.

\subsubsection{Experimentation}

In order to conduct the investigation, an experiment was designed in a controlled CNCEDM (Computer Numerically Controlled-Electro Discharge Machine) wire cutting environment (Figure 1), at "The National Small Industries Corporation Ltd." (NSIC) Aligarh, India.

Three levels of Angle of Abduction, namely 45, 55 and 60 degrees (Figure 2), were considered on the basis of the findings discussed in the related works and comprehensive surveys conducted at various EDM centers. Before actual start of the experiment, each of the subjects was asked to go through the instruction sheet served by the experimenter. Specific time interval was allowed to perform the actual task of the data entry for one set of the experimental condition. To start and stop the task, instruction was given through prerecorded voice on a recorder. Data entry time taken by the user constituted the index of the human performance. The performance of each subject at a pre-specified time was recorded (Figure 3) through entering a specially designed coded computer program on Electra, Maxi-cut-e CNC Wire-cut EDM for performing single pass cutting of alloy steel $(\mathrm{HCHCr})$ work piece. The entered (data entry) program had the following specifications:

- Work piece shape----------- rectangular

- Work piece height--------- 24 millimeters

- Wire material ------------- brass alloy

- Wire diameter ------------- 0.25 millimeter

- Angle of cut ------------- vertical

- Work piece hardness--------56 HRC

- Length of cut------------------ 10 millimeters

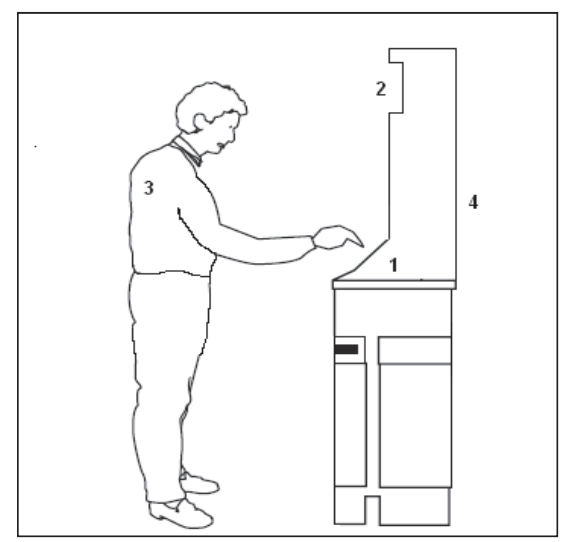

Fig. 1. Schematic representation of experimental setup: (1) Key-board (2) Visual display (3) Subject (4) CNC-EDM Control panel. 


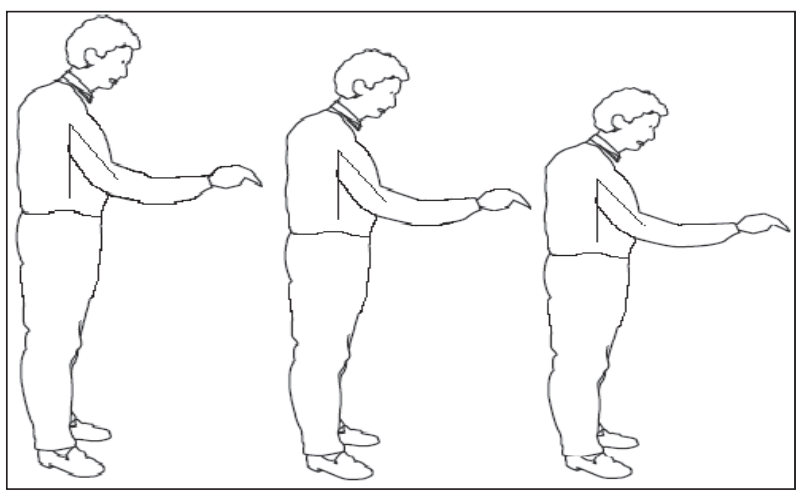

Fig. 2. Showing the abduction angles (45, 55 and 60 degrees) for $5^{\prime} 9^{\prime \prime}, 5^{\prime} 6^{\prime \prime}$ and $5^{\prime} 4^{\prime \prime}$ tall subjects, respectively.

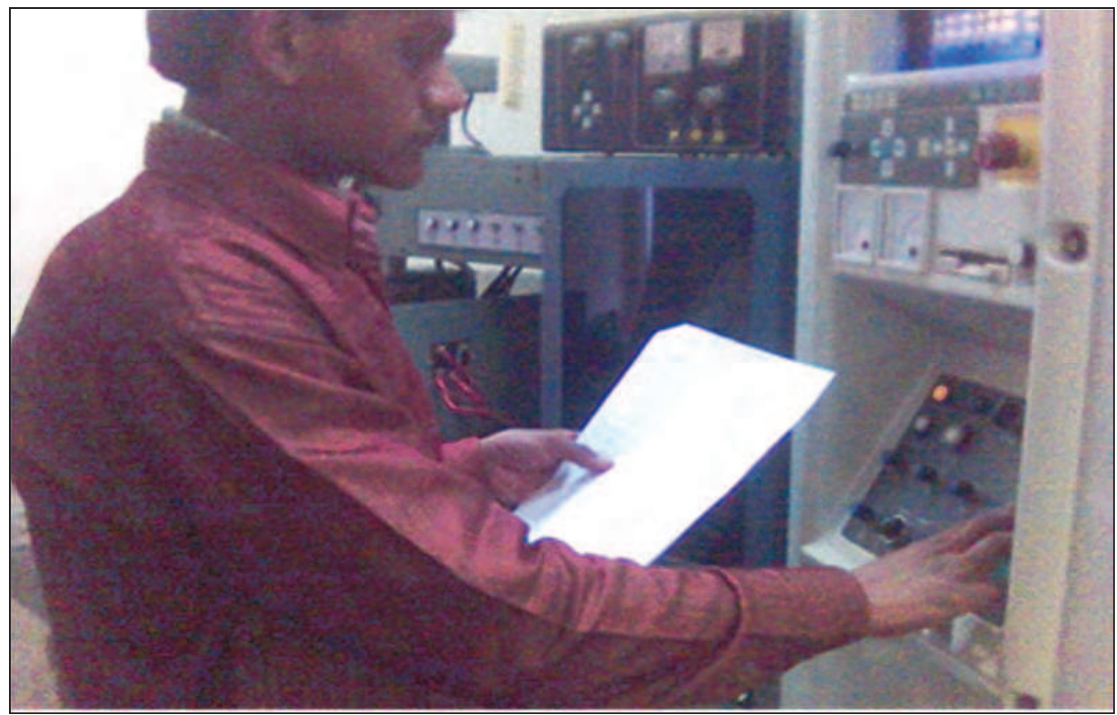

Fig. 3. Picture showing subject performing the data entry task.

\subsubsection{Statistical analysis}

The experimental data collected, in terms of subject's performance in a CNC-EDM environment, was investigated using statistical analysis with repeated measures. A method of comparison of the mean was used to determine the optimum level of Angle of Abduction.

\subsubsection{Results I}

The analysis of variance pertaining to the single factor repeated measure type of statistical design was performed over the data collected. The result is shown in the analysis of variance (ANOVA) Table-1; 


\begin{tabular}{|c|c|c|c|c|c|}
\hline S & $\begin{array}{c}\text { Type III } \\
\text { Sum of } \\
\text { Squares }\end{array}$ & $\mathrm{df}$ & $\begin{array}{c}\text { Mean } \\
\text { Square }\end{array}$ & F-value & P-value \\
\hline AA & 40.571 & 2 & 20.286 & 158.204 & $<0.0001$ \\
\hline E & 6.539 & 51 & 0.128 & & \\
\hline T & 2121.011 & 54 & & & \\
\hline
\end{tabular}

Table 1. Summary of Analysis of Variance. S-Source, AA- Angle of Abduction, E-Error, TTotal, df- degree of freedom.

F-ratio was used for testing the statistical hypothesis, and the level of significance for the test was set to 0.01 . It was concluded that;

(i) The null hypothesis, "Angle of Abduction does not significantly affect the operator's performance in a CNC-EDM environment", was rejected, because of the aggregate's mean time difference (performance data in terms of time). (ii) Null hypothesis rejected because the F-value $_{\mathrm{ov}}=158.204$ (from Table-1) was greater than $\left[\mathrm{F}_{0.01}(2,51)\right]_{\mathrm{cv}}=5.0472$ obtained from the F-table using the values for degrees of freedom $(2,51)$. [Where ov $=$ observed value and $c v=$ critical value]. (iii) Null hypothesis rejected because the P-value for F-value $=158.204$ was found to be less than 0.0001 i.e. $(p<0.0001)$, which was less than the set significance level $(\alpha=$ $0.01)$.

Since the angle of abduction had statistically significant effect so far as the data entry task was concerned, an attempt was made to develop a mathematical model to search for the relationship between human performance and the abduction level. Then linear and nonlinear regression analyses were performed. For the case of non-linear, exponential, hyperbolic and power function models were examined. The criterion fixed for selecting the best model was the value of the co-efficient of determination, $\mathrm{R}^{2}$, i.e., the best one would have the highest value of $\mathrm{R}^{2}$. Proceeding this way the exponential model was found to have the maximum value $(0.8852)$ of the $\mathrm{R}^{2}$. The best fit model had the following form:

$$
\mathrm{Y}=0.4625 * \mathrm{X}^{2}-1.8295 * \mathrm{X}+7.2525
$$

Where, $\mathrm{Y}=$ Human performance in a CNC-EDM environment and $\mathrm{X}=$ Angle of abduction level.

For the above mathematical model, data were generated and a graph was drawn showing relationship between the human performance and angle of abduction level (Figure 4).

\subsubsection{Statistical conclusion}

The null hypothesis stated above was rejected since $\mathbf{F}_{\text {ov }}=158.204$ was greater than $F_{\mathrm{cv}}=\mathbf{5 . 0 4 7 2}$. Furthermore, the computed probability value (p-value) i.e. $[p<0.0001]$ meant that the test was strongly significant at 1\%; hence Ho (null hypothesis) must be unequivocally rejected at the critical value of $1 \%$ because 0.0001 is $<<0.01$. Thus the above result indicated that the null hypothesis was rejected and it was found that the angle of abduction had a significant effect on human performance in a CNC-EDM environment. 
Variation in performance under different levels of angles of abduction was shown graphically in Figure 4. To establish which one out of the three considered angles of abduction was optimal, the data was further analyzed by the method of mean comparison proposed by Winer (1971).

\begin{tabular}{|c|c|c|c|c|c|}
\hline Contrast & $\begin{array}{c}\text { Contrast } \\
\text { sum of } \\
\text { square }\end{array}$ & $\mathrm{df}$ & $\begin{array}{c}\text { Mean } \\
\text { square }\end{array}$ & F-value & P-value \\
\hline 2 vs3 & 8.1225 & 1 & 8.1225 & 63.46 & $<0.0001$ \\
\hline 1 vs $(2,3)$ & 32.4723 & 1 & 32.4723 & 253.69 & $<0.0001$ \\
\hline
\end{tabular}

Table 2. Summary of the analysis.

Where; 1: First treatment mean (at an angle of abduction of 45 degrees), 2: Second treatment mean (at an angle of abduction of 55 degrees), 3: Third treatment mean (at an angle of abduction of 60 degrees).

Analysis in Table-2 shows that all contrasts were significant, because; (i) F-value ${ }_{\mathrm{ov}}=63.46$ and F-value $_{\mathrm{ov}}=253.69$, were greater than $\left[\mathrm{F}_{0.01}(1,51)\right]_{\mathrm{cv}}=7.1595$ (obtained from F-table). [Where ov $=$ observed value and $c v=$ critical value]. (ii) $\mathrm{P}$-values for both $\mathrm{F}_{\text {-value }}$ ov were found to be less than 0.0001 i.e. $(p<0.0001)$, which was less than the set significance level i.e. $\alpha=0.01$.

Furthermore, analysis showed that there was a significant difference between aggregates and the contrast [2 vs 3] was marginally significant however, the F-value 253.69 for the contrast $[1$ vs $(2,3)]$ was more significant, so the second contrast hypothesis was rejected. This indicated that a 45 degree angle of abduction level results in optimal operator performance (Figure 4).

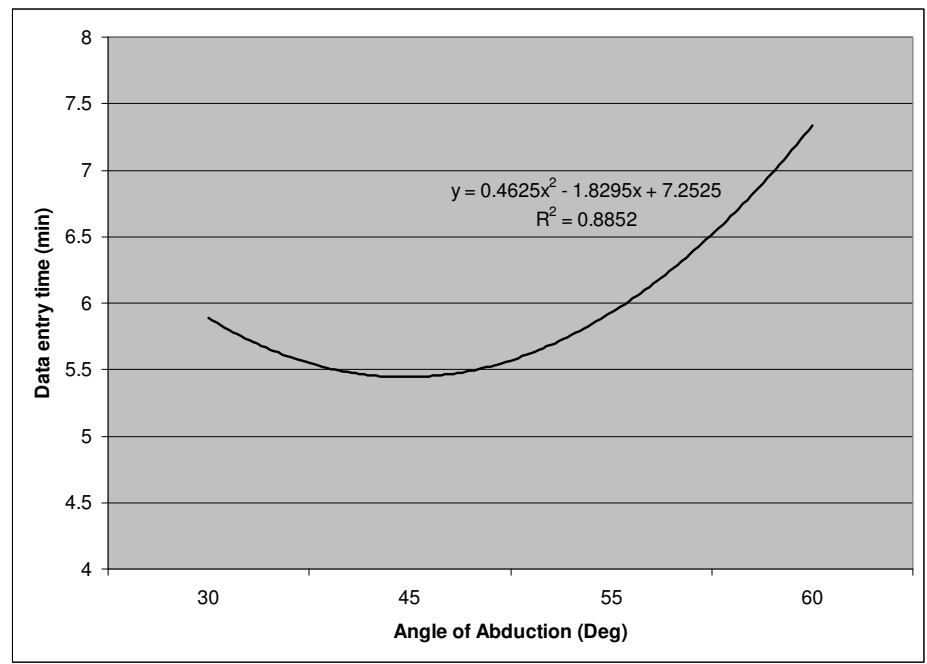

Fig. 4. Graph showing the performance in terms of data entry task time versus various levels of angle of abduction. 


\subsection{Study II}

\subsubsection{Subjects}

Experimental investigation was carried out with three groups of 18 subjects each. Groups were divided according to the variation in height of the subjects; i.e. (Group1) - Subjects of height 5' 9", (Group2) - Subjects of height 5' 6" and (Group3) - Subjects of height 5' 4". All subjects were male, age varied from $21-26$ years with mean age of 23.72 yrs (S.D $=1.592)$.

\subsubsection{Experimentation}

In order to conduct the investigation, an experiment was designed in a controlled CNCEDM (Computer Numerically Controlled-Electro Discharge Machine) wire cutting environment, at "The National Small Industries Corporation Ltd." (NSIC) Aligarh, India.

Three levels of Viewing Angle, namely 15, 21 and 28 degrees above horizontal (Figure 5) were considered on the basis of findings discussed in the related works and comprehensive surveys conducted at various EDM centers. Before actual start of the experiment, each of the subjects was asked to go through the instruction sheet served by the experimenter. Specific time interval was allowed to perform the actual error searching task for one set of the experimental condition. To start and stop the task, instruction was given through prerecorded voice on a recorder. Errors were incorporated in the specially designed coded computer program (as used for study I on Electra, Maxi-cut-e Wire-cut EDM) for performing single pass cutting of alloy steel $(\mathrm{HCHCr})$ work piece. Error searching time constituted the index of the human performance. The performance of each subject at a prespecified time was recorded through error searching task (Figure 6).

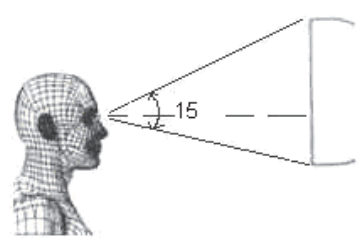

(a)

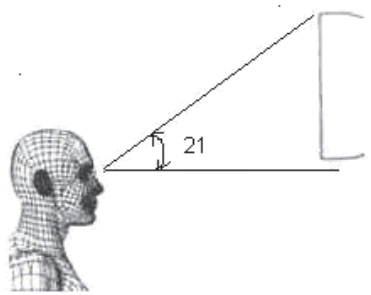

(b)

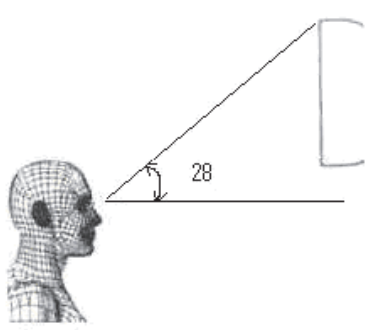

(c)

Fig. 5. Showing the EDM monitor and considered viewing angles for (a) 5' $5^{\prime \prime}$, (b) $5^{\prime} 6^{\prime \prime}$ and c) 5'4" height subjects, respectively. 


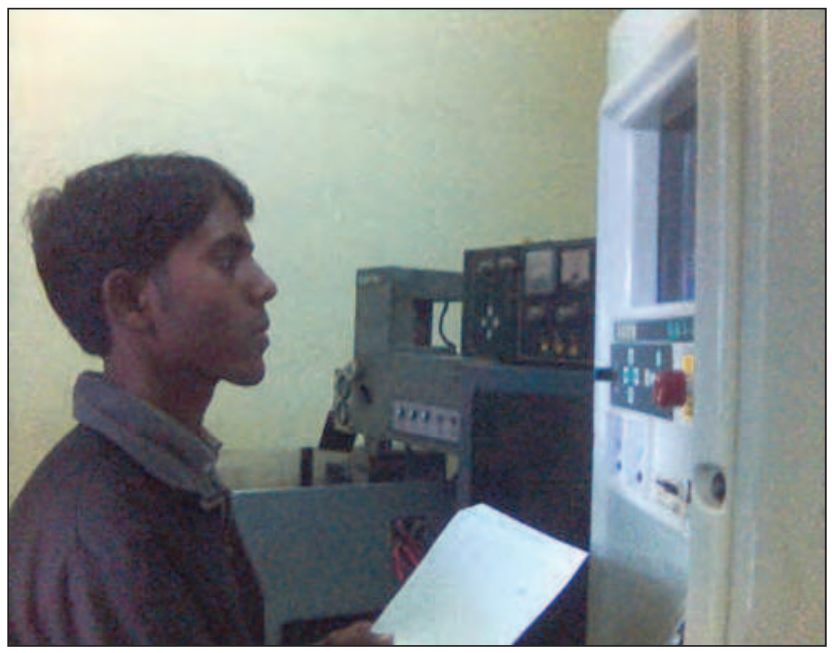

Fig. 6. Picture showing subject performing the error searching task.

\subsubsection{Statistical analysis}

The experimental data collected, in terms of subject's performance in a CNC-EDM environment, was investigated using statistical analysis with repeated measures. A method of comparison of the mean was used to determine the optimum level of viewing angle.

\subsubsection{Results II}

The analysis of variance pertaining to the single factor repeated measure type of statistical design was performed over the data collected. The result is shown in the analysis of variance (ANOVA) Table 3;

\begin{tabular}{|c|c|c|c|c|c|}
\hline S & $\begin{array}{c}\text { Type III } \\
\text { Sum of } \\
\text { Squares }\end{array}$ & df & $\begin{array}{c}\text { Mean } \\
\text { Square }\end{array}$ & F-value & P-value \\
\hline VA & 17.297 & 2 & 8.648 & 80.932 & $<0.0001$ \\
\hline E & 5.450 & 51 & 0.107 & & \\
\hline T & 858.501 & 54 & & & \\
\hline
\end{tabular}

Table 3. Summary of Analysis of Variance, S-Source, VA- Viewing Angle, E-Error, T-Total, df-degree of freedom.

F-ratio was used for testing the statistical hypothesis, and the level of significance for the test was set to 0.01. It was concluded that; (i) The null hypothesis, "Viewing Angle does not significantly affect the operator's performance in a CNC-EDM environment ", was rejected because of the aggregate's mean time difference (performance data in terms of error 
searching time). (ii) Null hypothesis rejected because the F-value $_{\text {ov }}=80.932$ (see Table 3) was greater than $\left[\mathrm{F}_{0.01}(2,51)\right]_{\mathrm{cv}}=5.0472$ obtained from the F-table using the values for degrees of freedom $(2,51)$. [Where ov $=$ observed value and $c v=$ critical value]. (iii) Null hypothesis rejected because the P-value for F-value $=80.932$ was found to be less than 0.0001 i.e. $(p<0.0001)$, which was less than the set significance level $(\alpha=0.01)$.

Since the viewing angle had statistically significant effect so far as the error searching task was concerned, an attempt was made to develop a mathematical model to search for the relationship between human performance and the viewing level. Then linear and non-linear regression analyses were performed. For the case of non-linear, exponential, hyperbolic and power function models were examined. The criterion fixed for selecting the best model was the value of the co-efficient of determination, $\mathrm{R}^{2}$, i.e., the best one would have the highest value of $\mathrm{R}^{2}$. Proceeding this way the exponential model was found to have the maximum value (0.774) of the $R^{2}$. The best fit model had the following form:

$$
\mathrm{Y}=0.025 * \mathrm{X}^{2}-1.0724 * \mathrm{X}+15.067
$$

Where, $\mathrm{Y}=$ Human performance in a CNC-EDM environment and $\mathrm{X}=$ Viewing Angle level.

For the above mathematical model, data were generated and a graph was drawn showing relationship between the human performance and viewing angle level (see Figure 7).

\subsubsection{Statistical conclusion}

The null hypothesis stated above was rejected since $F_{\mathrm{ov}}=80.932$ was greater than $\mathrm{F}_{\mathrm{cv}}=$ 5.0472 (obtained from F-table). Furthermore, the computed probability value (p-value) i.e. $[\mathrm{p}<0.0001]$ meant that the test was strongly significant at $1 \%$; hence Ho (null hypothesis) must be unequivocally rejected at the critical value of $1 \%$ because 0.0001 is $<<0.01$. Thus, the above result indicated that the null hypothesis was rejected and it was found that the viewing angle had a significant effect on human performance in a CNC-EDM environment. Variation in performance under different levels of viewing angle was shown graphically in Figure 7. To establish which one out of the three considered viewing angles was optimal, the data was further analyzed by the method of mean comparison proposed by Winer (1971).

\begin{tabular}{|c|c|c|c|c|c|}
\hline Contrast & $\begin{array}{c}\text { Contrast } \\
\text { sum of } \\
\text { square }\end{array}$ & df & $\begin{array}{c}\text { Mean } \\
\text { square }\end{array}$ & F-value & P-value \\
\hline 2 vs 3 & 2.0736 & 1 & 2.0736 & 19.38 & $<0.0001$ \\
\hline 1 vs $(2,3)$ & 15.3228 & 1 & 15.3228 & 143.20 & $<0.0001$ \\
\hline
\end{tabular}

Table 4 . Summary of the analysis.

Where; 1: First treatment mean (at a viewing angle of 15 degrees), 2: Second treatment mean (at a viewing angle of 21 degrees), 3: Third treatment mean (at a viewing angle of 28 degrees). 
Analysis in Table 4 shows that all contrast were significant, because; (i) F-value $\mathrm{ov}=19.38$ and F-value $_{\mathrm{ov}}=143.20$, were greater than $\left[\mathrm{F}_{0.01}(1,51)\right]_{\mathrm{cv}}=7.1595$ (obtained from F-table). [Where $o v=$ observed value and $c v=$ critical value]. (ii) P-values for both F-value $\mathrm{ov}_{\mathrm{ov}}$ were found to be less than 0.0001 i.e. $(p<0.0001)$, which was less than the set significance level i.e. $\alpha=0.01$.

Furthermore, analysis showed that there was a significant difference between aggregates and the contrast [2 vs 3] was marginally significant however, the F-value 143.20 for the contrast $[1$ vs $(2,3)]$ was more significant, so the second contrast hypothesis was rejected. This indicated that a 21 degree viewing angle level results in optimal operator performance (Figure 7).

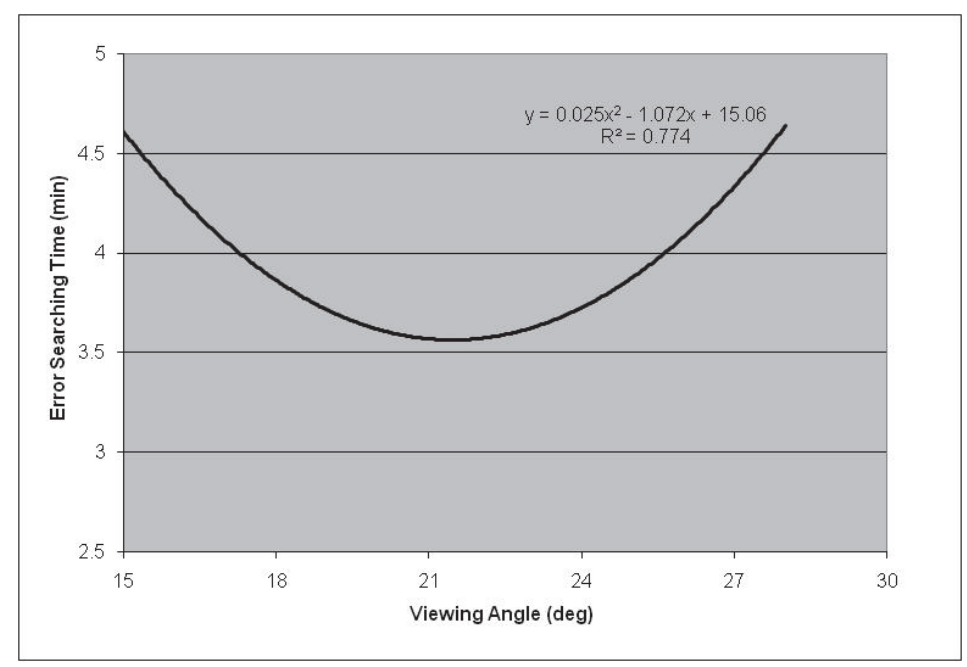

Fig. 7. Graph showing the performance in terms of error searching time versus various levels of viewing angle.

\section{Discussion}

World Health Organization (WHO) and Occupational Safety and Health Administration (OSHA) consider the cause of work related musculoskeletal diseases as multi-factorial. Management and workers in the recent scenario of automation are greatly concerned with working environment, ergonomics, quality of work and occupational safety and health. The development in information and communication technologies and specialized work requiring repetitive task add up to a need for human-machine interface design. Ergonomists are concerned with the complex physical relationships between peoples, machines, job demands and work methods. Nowadays major emphasis is on preventing musculoskeletal injuries in the work place. Prevention of these injuries is accomplished by understanding biomechanics and physiology of work, through the use of biomechanical models, laboratory simulations, field studies and job analysis.

Musculoskeletal disorders (MSDs) is a health disorder caused by repetitive motion, inadequate working posture, excessive exertion of strength, body contact with sharp surface, vibration, temperature, etc. MSDs can be minimized by prevention and 
management. Benefits from the prevention and management of MSDs show improvement of work environment, the relation between the labor and management, productivity and decrease in lost work days. From a long-term viewpoint, it can reduce financial losses and create the image of safe work place. MSDs are widespread and occur in all kind of jobs. However, work related musculoskeletal disorders are not only health problems; they also are a financial burden to society. The costs are related to medical costs, decreased productivity, sick leave and chronic disability (Danuta, 2010). Many studies proved that load sustained at very low levels can be a factor in MSDs development. Despite the fact that there is widespread awareness of the problem and measures to limit development of MSDs are being undertaken, according to an European survey up to $25 \%$ of workers report back pain and $23 \%$ muscular pain.

Some amounts of optical radiation are beneficial for humans but excessive exposure can cause many negative health effects to the skin and eyes and also can affect the immune system. Biological effects can be induced only by absorbed radiation. We could distinguish two types of reactions in biological tissues induced by optical radiation: photochemical and thermal. Exposure limit values represent conditions under which it is expected that nearly all individuals may be repeatedly exposed without acute adverse effects and based upon best available evidence, without noticeable risk of delayed effects.

In recent years, human-machine interface system has become one of the most promising areas for an ergonomist for designing, research and development. With the rapid technological advancement across the world, various new industries are emerging in large numbers day by day and the problems related with working environment are also increasing. The operator's posture, work place as well as machine and their interaction environment indicate significant effect on the performance. The optimum working environment can be designed if all the factors influencing the human performance are considered together. Factors such as angle of abduction and viewing angle are crucial from the ergonomic design point of view. Present work was taken to develop a better understanding of the effect of angle of abduction and viewing angle in a HMI environment. This work revealed that a 45 degree abduction angle and 21 degree viewing angle gives the optimal performance as far as human-CNC machine interaction environment is concerned.

The above mentioned findings in some way or the other are similar to those obtained by some earlier investigators also. Susan et al. (2006), for example, found significant reductions in the muscle activity by modifying the workstation arrangement of an ultrasound system's control panel. Similarly, Dennerlein et al. (2006) based upon their study revealed that designing for the optimal configuration of a computer controlled workstation was necessary to eliminate the postural discomfort. Also, Smith et al. (2002) found the optimum height of the table to position the handles of the laparoscopic instrument to minimize the discomfort. Another study by Lehman et al. (2001) explored that the modified workplace design of a retail supermarket industry minimizes the postural stress, fatigue and discomfort. Present study was also supported by Hongwei et al. (2002), which identified differences in various body measurements between occupational groups in the USA. The researcher concluded that the body size or the body segment measurements of some occupational groups differ significantly. The present finding was supported by Peter et al. (2006). The study revealed that the task completion in a computer controlled environment result the higher shoulder muscle activity, larger 
range of the motion and the larger velocities and acceleration of the upper arm. The finding was also supported by Fine et al. (2000). It was concluded in the referred study that the shoulder flexion or abduction is predictive of chronic or recurrent shoulder disorder. Therefore, based upon the research reviews, it can be significantly concluded that the anthropometric factors play a key role in the effective and efficient ergonomic design of the human-CNC machine interaction environment.

Furthermore, Kong-King et al., (2007), for example, found significant reductions in the eye muscle activity by modifying the workstation arrangement of an electronic paper displays. Dennerlein et al., (2006) based upon their study revealed that designing for the optimal configuration of a computer controlled workstation was necessary to eliminate the postural discomfort. In a VDU work environment, Svensson et al., (2001) found the optimum viewing angle which resulted lower load on the neck and shoulders. Also, Jan et al., (2003) explored that high viewing angle affects the activity of the neck extensor muscles. Results of the present study are supported by those of Batten et al., (1998), who determined the optimum viewing angle in a food service industry. The present findings also agree with the observations of Mon-Williams et al., (1998). This study revealed that as vertical gaze angle is raised or lowered, the effort required to binocular system also changes. Hence it can be concluded that the visual factor play a key role in the effective and efficient ergonomic design of the human-CNC machine interaction environment.

It is essential from the ergonomic point of view that the work place design of a $\mathrm{CNC}$ machine environment be compatible with the biological and psychological characteristics of the operators. The effectiveness of the human-CNC machine combination can be greatly enhanced by treating the operator and the $\mathrm{CNC}$ machine as a unified system. When the $\mathrm{CNC}$ operator is viewed as one component of a HMI system, the human characteristics pertinent to the ergonomic design are physical dimensions, capability for the data sensing, capability for the data processing, capability for the learning etc. Quantitative information about these human characteristics must be co-ordinate with the data on CNC machine characteristics, if maximum human-machine integration is to be achieved. The findings of the present work revealed that the levels of the angle of abduction and viewing angle have a statistically significant effect on the performance of the CNC-EDM operators. However, a 45 degree abduction angle and 21 degree viewing angle emerged to be the one which appears to offer a high level of compatibility in a human-CNC machine interface environment. Finally, it is observed that the application of ergonomics in the design of human-CNC machine interface would help to increase machine performance and productivity, but mostly help human operator to be comfortable and secure. Since nowadays, majority of the companies acquired $\mathrm{CNC}$ machines in order to be competitive, ergonomic and safety aspects must be considered.

\section{Conclusion}

In a human-machine interaction environment, machines are used to aid humans in the execution of various tasks. Therefore, human-machine interaction system should be designed to match the capabilities, limitations and characteristics of human beings. This work demonstrated that the angle of abduction and viewing angle have a marked effect on the operator's performance. 
On the basis of the studies carried out, the following concluding remarks are drawn;

i. The level of angle of abduction has a significant effect on the performance of CNC-EDM operators.

ii. Findings of this work indicate that CNC-EDM systems should be re-designed so as to achieve a 45 degree angle of abduction for optimal performance.

iii. The level of viewing angle has a significant effect on the performance of CNC-EDM operators.

iv. Findings of this work indicate that CNC-EDM systems should be re-designed so as to achieve a 21 degree viewing angle for optimal performance.

The finding of this work can be directly applied to the practical field which will improve the design of a CNC-EDM system. This work suggests that those responsible for the function and operation of CNC-EDM workstations would have to redesign the system to reduce injuries, as far as visual, musculoskeletal and other related problems are concerned.

The present results are very important for the system designers of tomorrow. It is expected that more studies would be undertaken in this regard in near future and the new humanCNC machine interaction systems would be designed accordingly.

Bring to a close, the application of ergonomic principles in the design of human-CNC machine interface, would help to increase machine performance and productivity, but mostly help human operator to be comfortable and secure. Since at present time the vast majority of the companies acquired Automated Manufacturing Technology in order to be competitive, ergonomic and safety aspects must be considered.

\section{Acknowledgment}

The author would like to acknowledge the support provided by the national small industries corporation (NSIC), a government of India undertaking, Aligarh, India.

\section{References}

Alan R. H., Bente J. \& Karen (2003). Intramuscular pressure and EMG relate during static concentrations but dissociate with movement and fatigue. Journal of Physiology,Vol-10, 1-31.

Antony N.T. \& Keir P.J. (2010). Effects of posture, movement and hand load on shoulder muscle activity. Journal of Electromyography and Kinesiology, Vol- 20(2), 191- 198.

Ayako T., Hiroshi J., Maria B.. Villanueva G, Midori S. \& Susumu S. (2002). Effects of the liquid crystal display tilt angle of a notebook computer on posture, muscle activities and somatic complaints. International journal of industrial ergonomics, Vol-29(4), 219-229.

Batten D.M., Schultz K.L. \& Sluchak T.J. (1998). Optimal viewing angle for touch screen displays: Is there such a thing? International journal of industrial ergonomics, Vol22(4-5), 343-350.

Bendix T., Krohn L., Jessen F. \& Aaras A. (1985). Trunk posture and trapezius muscle load while working in standing, supported-standing, and sitting positions. Spine, Vol-10 (5), 433-439. 
Burgess-Limerick, Robin, M. W., Mark C. \& Vanessa L. (2000). Visual Display Height. The Journal of the Human Factors and Ergonomics Society, Vol- 42, 140-150.

Choudhury, M.D. Dewangan, K.N.. Prasanna K. G.V \& Suja P.L. (2005). Anthropometric dimensions of farm youth of the north eastern region of India. International Journal of Industrial Ergonomics, Vol-35(11), 979-989.

Danuta Roman-Liu (2010). Tools of Occupational Biomechanics in Application to Reduction of MSDs. 3rd International conference on AHFE, ISBN 978-1-4398-3499-2, Miami, Florida, USA, july 2010, Book-6(37), 367-376.

David K.,.Ong C.N., Phoon W.O \& Low A. (1988). Anthropometrics and display station preferences of VDU operators. Ergonomics, Vol-31(3), 337-347.

Dennerlein J.K. \& Johnson P.W. (2006). Changes in upper extremity biomechanics across different mouse positions in a computer workstation. Ergonomics, Vol-49, 14561469.

Fine L.J., Punnett L., Keyserling W.M., Herrin G.D. \& Chaffin D.B. (2000). Shoulder disorders and postural stress in automobile assembly work. Scandinavian Journal of Work, Environment and Health, Vol-26 (4), 283-291.

Fraser K., Burgess-Limerick R., Plooy A. \& Ankrum D.R. (1999). The influence of computer monitor height on head and neck posture. International journal of industrial ergonomics, Vol -23(3), 171-179.

Gielo-Perczak K., Matz S. \& An Kai-Nan (2006). Arm abduction strength and its relationship to shoulder geometry. Journal of Electromyography and Kinesiology, Vol-16(1), 6678.

Gutierrez S., Levy J.C., Frankle M.A., Cuff D., Keller T.S., Pupello D.R. \& Lee III W.E. (2008). Evaluation of abduction range of motion and avoidance of inferior scapular impingement in a reverse shoulder model. Journal of Shoulder and Elbow Surgery, Vol -17(4), 608-615.

Hongwei H., Daniel L. \& Karl S. (2002). Anthropometric differences among occupational groups. Ergonomics, Vol-45 (2), 136-152.

Jan S., Arnaud J. \& Arthur S. (2003). Posture, muscle activity and muscle fatigue in prolonged VDT work at different screen height settings. Ergonomics, Vol- 46, 714730.

Jung-Yong K. Min-Keun C. \& Ji-Soo P. (2003). Measurement of physical work capacity during arm and shoulder lifting at various shoulder flexion and ad/abduction angles. International Journal of Human Factors and Ergonomics in Manufacturing, Vol-13, 153-163.

Kong-King S. \& Der-Song L. (2007). Preferred viewing distance and screen angle of electronic paper displays. Applied Ergonomics, Vol-38 (5), 601-608.

Koroemer K. H.E. \& Hill S.G. (1986). Preferred line of sight angle. Ergonomics, Vol-29, 11291134.

Kuppuswamy A., Catley M., King N.K.K., Strutton P.H., Davey N.K. \& Ellaway P.H. (2008). Cortical control of erector spinae muscles during arm abductions in humans. International Journal of Gait and Posture, Vol-27(3), 478-484.

Lehman, K.R.. Psihogios J.P \& Meulenbroek R.G.J. (2001). Effects of sitting versus standing and scanner type on cashiers. Ergonomics, Vol-44, 719-738.

Levasseur A., Tetreault P., Guise J. de, Nuno N. \& Hagemeister N. (2007). The effect of axis alignment on shoulder joint kinematics analysis during arm abduction. International Journal of Clinical Biomechanics, Vol-22(7), 758-766.

Mon-Williams M., Pooly A., Burgess-Limerick R. \& Wann J. (1998). Gaze angle: a possible mechanism of visual stress in virtual. Ergonomics, Vol-41(3), 280-285. 
Mukhopadhyay P., O'Sullivan L. \& Gallwey T.J. (2007). Estimating upper limb discomfort level due to intermittent isometric pronation torque with various combinations of elbow angles, forearm rotation angles, force and frequency with upper arm at $90^{\circ}$ abduction. International Journal of Industrial Ergonomics, Vol-37(4), 313-325.

Peter W. J. \& Jack T. D. (2006). Different computer tasks affect the exposure of the upper extremity to biomechanical risk factors. Ergonomics, Vol-49, 45-61.

Shahnavaz H. (2009). Ergonomics intervention in industrially developing countries, Ergonomics in developing regions: Needs and applications, Taylor \& Francis, 4158.

Shahnavaz H., Naghib A. \& Samadi S. (2010). Macro and Micro Ergonomic Application in a Medium Sized Company. 3rd International conference on AHFE, ISBN 978-1-43983499-2, Miami, Florida, USA, Book-6(35), 340-354.

Shallaly G.E. \& Cuschieri A. (2006). Optimum viewing distance for laparoscopic surgery. International Journal of Surgical Endoscopy, Vol-20, 1879-1882.

Smith D.T., Ball K., Ellison A. \& Schenk T. (2010). Deficits of reflexive attention induced by abduction of the eye. International Journal of Neuropsychologia, Vol-48(5), 12691276.

Smith, W.D. Berquer R.\& Davis S. (2002). An ergonomic study of the optimum operating table height for laparoscopic surgery. Surgical Endoscopy, Vol-16, 416-421.

Susan. L. M. \& Andy M. (2006). Surface EMG evaluation of sonographer scanning postures. Journal of diagnostic medical sonography, Vol-22, 298-305.

Svensson H.F. \& Svensson O.K. (2001). The influence of the viewing angle on neck-load during work with video display units. Journal of Rehabilitation Medicine, Vol-33, $133-136$.

Terrier A., Vogel A., Capezzali M. \& Farron A. (2008). An algorithm to allow humerus translation in the indeterminate problem of shoulder abduction. International Journal of Medical Engineering and Physics, Vol-30(6), 710-716.

Westgaard, R. H. Aaras A. \& Stranden E. (1988). Postural angles as an indicator of postural load and muscular injury in occupational work situations. Ergonomics, Vol-31 (6), 915-933.

Westlander G., Viitasara E., Johansson A. \& Shahnavaz H. (1995). Evaluation of an ergonomics intervention programme in VDT workplaces. Applied ergonomics, Vol-26(2), 83-92.

Wickham J., Pizzari T., Stansfeld K., Burnside A. \& Watson L. (2010). Quantifying normal shoulder muscle activity during abduction. International Journal of Electromyography and Kinesiology, Vol-20(2), 212-222.

Winer. B.J. (1971). Statistical principles in experimental design, $2^{\text {nd }}$ edition, Tokyo: Mc GrawHill Kogakusha Ltd.

Yeow P. \& Sen R. (2002).The promoters of ergonomics in industrially developing countries, their work and challenges. Proceedings: $3^{\text {rd }}$ International cyberspace conference on Ergonomics, the CybErg 2002.

Yun G. L., Myung H. Y., Hong J. E. \& Sang H. L. (2001). Results of a survey on the awareness and severity assessment of the upper-limb work-related musculoskeletal disorders among the female bank tellers in Korea. International Journal of Industrial Ergonomics, Vol-27, 347-357.

Yunis A.A. M. (2005). Anthropometric characteristics of the hand based on laterality and sex among Jordanian. International Journal of Industrial Ergonomics, Vol-35(8), 747754 . 


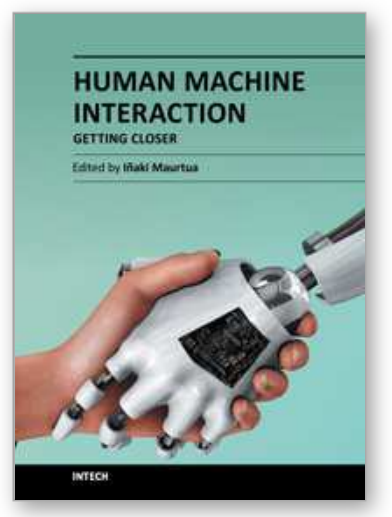

\author{
Human Machine Interaction - Getting Closer \\ Edited by Mr Inaki Maurtua
}

ISBN 978-953-307-890-8

Hard cover, 260 pages

Publisher InTech

Published online 25, January, 2012

Published in print edition January, 2012

In this book, the reader will find a set of papers divided into two sections. The first section presents different proposals focused on the human-machine interaction development process. The second section is devoted to different aspects of interaction, with a special emphasis on the physical interaction.

\title{
How to reference
}

In order to correctly reference this scholarly work, feel free to copy and paste the following:

Imtiaz Ali Khan (2012). Ergonomic Design of Human-CNC Machine Interface, Human Machine Interaction Getting Closer, Mr Inaki Maurtua (Ed.), ISBN: 978-953-307-890-8, InTech, Available from:

http://www.intechopen.com/books/human-machine-interaction-getting-closer/ergonomic-design-of-human-cncmachine-interface

\section{INTECH}

open science | open minds

\section{InTech Europe}

University Campus STeP Ri

Slavka Krautzeka 83/A

51000 Rijeka, Croatia

Phone: +385 (51) 770447

Fax: +385 (51) 686166

www.intechopen.com

\section{InTech China}

Unit 405, Office Block, Hotel Equatorial Shanghai

No.65, Yan An Road (West), Shanghai, 200040, China

中国上海市延安西路65号上海国际贵都大饭店办公楼 405 单元

Phone: +86-21-62489820

Fax: $+86-21-62489821$ 
(C) 2012 The Author(s). Licensee IntechOpen. This is an open access article distributed under the terms of the Creative Commons Attribution 3.0 License, which permits unrestricted use, distribution, and reproduction in any medium, provided the original work is properly cited. 